\title{
We need to address the migration backlash
}

Written by: Stefano Scarpetta, Director, OECD Directorate for Employment, Labour and Social Affairs

Last update: 10 March 2017

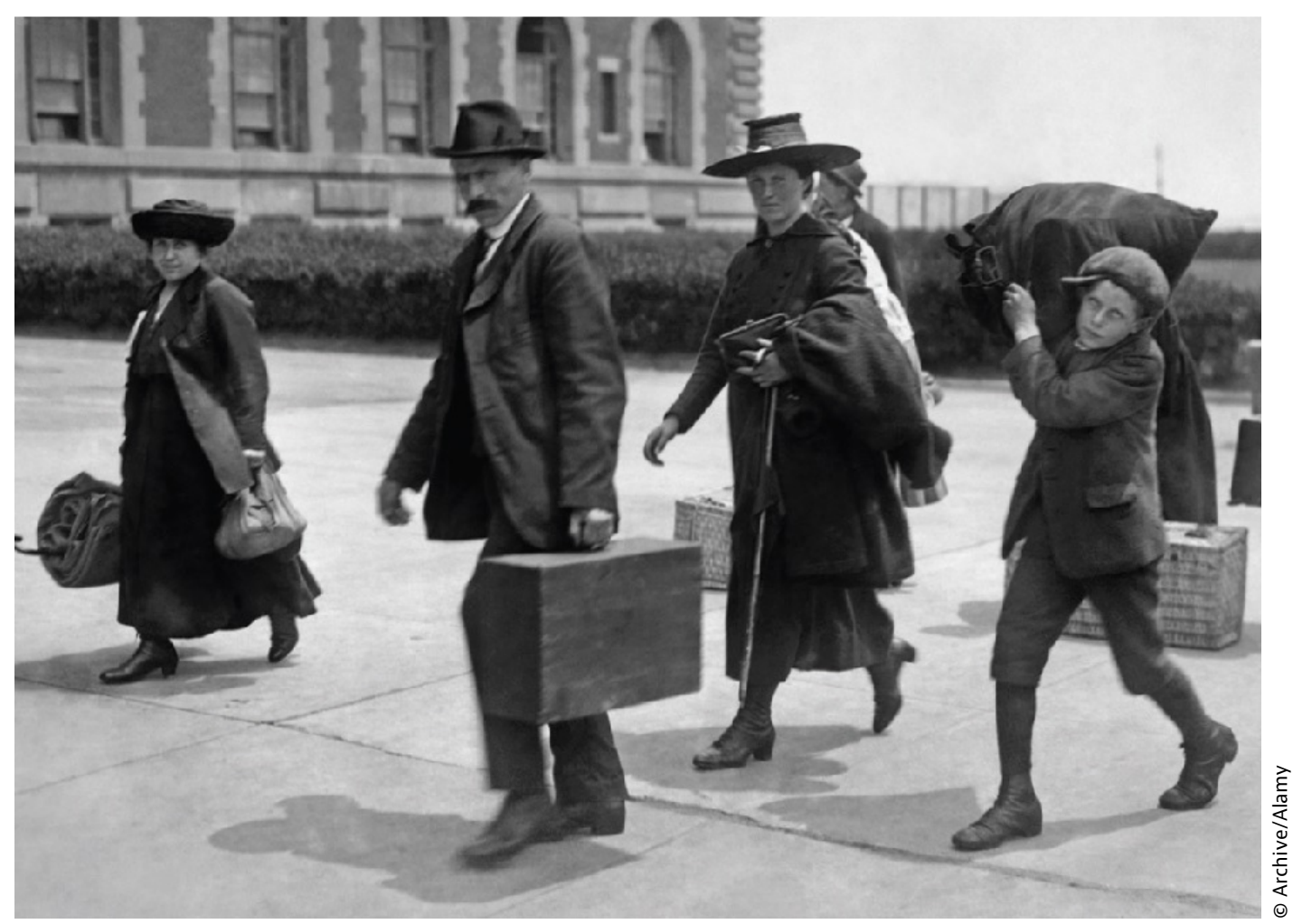

Human resources: Just some of the 12 million immigrants that arrived in the US via Ellis Island from 1892 to 1954

The public is losing faith in the capacity of governments to manage migration. Opinion polls in a wide range of countries suggest that the share of the public holding extreme antiimmigration views has grown in recent years and that these extreme views are more frequently heard in public debates. In part, this is due to the perception that no end is in sight for large migration inflows and that countries have lost control over them. 
People are concerned about the short-term impact of large inflows of migrants, and refugees in particular, and many feel that migration is threatening their economic, social as well as personal security. Common concerns are that migration is unmanaged and borders are not secured; immigrants stretch local services, such as social housing, health and education, to the detriment of local populations; immigration benefits the rich, with the poor finding themselves competing with immigrants for jobs, and wages for low-skilled work depressed; and many migrants do not want to integrate and may even oppose the values of host societies.

In most countries though, refugee flows are still a relatively small part of overall migration. The OECD has collected a wealth of evidence showing that the medium and longer term effects of migration on public finance, economic growth and the labour market are generally positive. But this message is not getting through. However much the demographic and macro-economic arguments for migration are true, they seem abstract and long-term to many people. As a result, they have only a limited impact on public opinion, and mainly preach to the converted. Governments need to develop better, more practical arguments if they are to counter anti-immigration voices.

The truth of the matter is that migration is a fact of life and is here to stay. About 120 million people living in OECD countries were born elsewhere and one person out of five is either a migrant or was born to a migrant parent. More than 4 million new permanent migrants settled in OECD countries each year on average over the past decade.

If we want to reap the full benefits of migration and to heal the social schisms that seem to be appearing in too many countries, action is needed from policy-makers on three main fronts.

Countries must acknowledge and address the fact that the impact of migration is not the same for everyone. Immigrants are nearly always concentrated in specific regions and urban areas-often the most disadvantaged ones. The local impact of large-scale immigration may be far stronger than what is observed at the national level, and may be working in a different direction. In particular, OECD International Migration Outlook shows that large sudden inflows of migrants can aggravate longstanding structural problems and bottlenecks in local infrastructure, such as housing, transportation and education.

Similarly, although this is not usually the case, in some circumstances, large numbers of low-skilled migrants arriving in a particular area may have a negative impact on the local labour market prospects of low-skilled residents already present. Scaling up those local public services stretched by increased numbers of migrants is a necessary part of an effective policy response, as is ensuring that minimum wages and other labour market regulations are applied rigorously. 
Global challenges need global solutions. Leaving individual countries to deal with massive inflows, as recently witnessed with the refugee crisis, cannot address the problems adequately. International co-operation needs to be stepped up, with different countries making different contributions. [...]

We need a new generation of effective migration policies adequate to the challenges of the 21st century. These policies must be global, because no country can deal with large, unexpected migration flows alone and in isolation. And local, because policies must promote quick and effective integration of those who are going to stay in the local community; and address the specific concerns of those who feel they do not experience direct benefits from migration and fear that it will challenge the basic values of the host society.

Unless systematic and co-ordinated action is taken in a timely way to acknowledge and vigorously address these concerns, migration policy will continue to seem abstract and elitist, at best trailing behind the problems it is supposed to be addressing. And, as is already apparent, the result is likely to be a more strident political populism.

Extract adapted from the editorial entitled "OECD countries need to address the migration backlash", in International Migration Outlook 2016, OECD Publishing.

\section{References}

International Migration Outlook 2016 http://dx.doi.org/10.1787/ migr_outlook-2016-en 